\title{
Sciendo
}

10.2478/topling-2019-0010

\section{"The authors have wasted their time...": Genre features and language of anonymous peer reviews}

\author{
Tatyana Yakhontova* \\ Ivan Franko National University of Lviv, Ukraine
}

\begin{abstract}
The anonymous peer review is an unpublished pre-publication review which evaluates research articles submitted to journals. This type of a review plays a special role in the genre landscape of Anglophone research by ensuring its appropriate quality and ethical standards. By performing this role, the peer review also realizes a didactic potential, as it motivates researchers to improve their investigations. This paper extends the existing research on the anonymous peer review and aims to deepen our understanding of this genre by analysing the overall functional organization of peer review texts and their prominent linguistic features shaped by three communicative functions "gatekeeping", evaluative, and didactic. It also attempts to compare the characteristics of peer reviews in two research fields ideologically and epistemologically distant from each other - applied linguistics and applied mathematics. The methodological framework of the study combines Swales's move analysis and a functional stylistic perspective developed within the East European linguistic context. The analysis has revealed a three-move structure of review texts and disclosed the roles of interpersonal markers, evaluative lexis and four types of directives in the realization of the communicative functions of the genre. The typologies of reviewers' comments and evaluative acts in reviews have also been suggested. Furthermore, the study has brought to light some quantitative and qualitative differences between the texts in two disciplines. It is anticipated that awareness of the linguistic conventions of anonymous peer reviews analysed in the paper will help researchers to perceive this genre as a valuable source of professional assistance and enlightenment.
\end{abstract}

\section{Key words}

genre, anonymous peer review, communicative functions, moves, interpersonal markers, stylistic features evaluative lexis, directives

\section{Introduction}

Genres of research communication - those formats and vehicles of knowledge production and dissemination - continue to attract the attention of linguists, even though a considerable amount of research on their pragmatic, structural and linguistic features has already been accumulated. Important social functions and conventions, evolving under the influence of societal changes and new technologies, make the texts of research genres an interesting and rewarding object of linguistic enquiry. In particular, this refers to the anonymous peer review (also called a referee's report) - an unpublished pre-publication reviewer's report which evaluates research articles submitted to journals (anonymous reviewing can also accompany other communication processes and genres, such as

\footnotetext{
* Address for correspondence: Tatyana Yakhontova, Ivan Franko National University of Lviv, 41 Doroshenka, Lviv, Ukraine. E-mail: tyakh@yahoo.com
} 
considering research projects for funding or conference abstracts for acceptance). This type of review plays a special role in the genre landscape of Anglophone global science and scholarship by playing a "gatekeeping" role, which ensures the appropriate quality of proposed research and helps to sustain ethical standards of investigations.

The anonymous review has its own, well-defined, place in the communicative process preceding the publication of the article, which usually undergoes the following stages: 1) the author submits an article to a chosen journal in his/her field; 2) the editor checks the article for its relevance to the journal and overall quality; 3 ) then the editor invites experts (usually, 1-3) from the same field of research that will act as reviewers; 4) invited reviewers evaluate the article according to a number of standard criteria, formulate recommendations as to its further fate ("accept", "minor revision", "major revision" or "reject"), and share their report with the author and the editor; 5) the editor makes a decision based on the received review and informs the author of it; 6) in the case of recommended revision of the article, the author makes changes and responds to the remarks and comments of each reviewer; 7) the editor takes the final decision on the submitted article. This rather lengthy process can have a cyclical nature (that is, the article can be revised and resubmitted several times). The criteria for evaluating articles depend on disciplinary factors and may vary from journal to journal, although, most generally, they will necessarily refer to content quality and originality of the article, robustness of the research design and methodology, organization and clarity of all its structural parts, and correspondence to the aims and scope of the journal.

The number of users of the anonymous review genre is quite limited. The producer of the genre is the reviewer, while its only recipients are the author of the reviewed article and the editor. However, this "secret" genre lies at the core of the publication process, performing the role of a communicative mechanism, which regulates the process of publishing. In particular, the peer review intends "to filter out work that has not been well planned, carried out, and written up... to ensure that the work is reported on correctly and that connections are made to other work that has already been published on the topic... to ensure that results have been correctly interpreted and that other possible interpretations of the results have been considered" (Paltridge, 2017, p. 25). By performing such a role, this genre also realizes a didactic potential, as it motivates researchers to improve the quality of their investigations.

Thus, the anonymous pre-publication article review seems to have three main intertwined communicative functions, or purposes: 1) "gatekeeping", 2) evaluative, and 3) didactic. This set of criterial purposes differentiates it from other genres belonging to the same network of evaluative texts, namely, from the published book review and review article. All the three genres share an evaluative function, although, in contrast to the "hidden" genre of the reviewer's report, the book review and review article appeal to a quite broad audience, informing it, respectively, of a published book or summarizing previous studies.

The special role of the anonymous review in supporting research processes undoubtedly accounts for the interest in it of specialists, coming from quite different spheres: editing and translation (e.g., Shashok, 2008; Uusiautti, 2016), philosophy, sociology of knowledge and information science (e.g., Hill and Provost, 2003; Lee, Sugimoto, Zhang and Cronin, 2013; Smith, 2006), writing teachers (e.g., Ball, 2013; Parfitt, 2012), and applied linguists (Belcher, 2007; Bocanegra-Valle, 2015; Englander, López-Bonilla, 2011; Fortanet, 2008; Fortanet-Gómez, 2008; Gosden, 2003; Johnson and Roen, 1992; Kourilova, 1998; Matsuda, Tardy, 2007; Mungra and Webber, 2010; Paltridge, 2015, 2017; Samraj, 2016; Tharirian and Sadri, 2013). While representatives of fields other than applied linguistics mostly discuss the role of the peer reviewing process and often criticize it for possible biases, linguists consider, as will be shown below, various features of the texts of reviews.

\subsection{An overview of linguistic research on peer reviews}

Since content and language of reviewers' comments and recommendations comprise the most important part of referees' reports, it is not surprising that they have been addressed by many researchers of this genre (Belcher, 2007; Gosden, 2003; Mungra and Webber, 2010; Samraj, 2016; Tharirian and Sadri, 2013).

In particular, Gosden (2003) studied comments in 40 reviews of scientific papers based on their referential classification into what he called Technical Detail, Claims, Discussion, References, and Format. The categories were further interpreted as Halliday's metafunctions - ideational, interpersonal 
and textual, which allow the revealing of the main interconnected aspects of a communicative event. The application of such a methodology has yielded quantitative data showing a preponderance of interpersonal orientation in reviewers' comments in the corpus under investigation.

Mungra and Webber (2010) analysed reviewers' remarks on 17 manuscripts submitted by medical researchers working in Italy to international journals. They stratified all the comments into two large groups - content (referring to scientific value and methodology of the reviewed articles) and language ones, which were subdivided according to a number of selected categories and then quantified. As this research has shown, content comments slightly prevail over the language ones. Following the same methodological line, Tharirian and Sadri (2013) analysed a corpus of reviewers' reports on the papers of Iranian graduate students submitted to international journals and also found out that content comments are more frequent than language ones, although the importance of the latter cannot be underestimated.

Belcher (2007) scrutinized the submission history of documents of an international journal in applied linguistics in order to clarify the role that peer reviewers play in providing (or not providing) access to off-network scholars (that is, those who live and work outside the so-called English-speaking centre). In the course of this research, she developed a typology of reviewers' comments based on nine text features (audience, topic, purpose, literature review, methods, results, discussion, significance, pedagogical implications, and language use), of which the comments of only two categories audience and topic - were not obviously critical. Furthermore, Belcher's quantitative data have demonstrated that language commentary is an important component of review texts. This observation has been supported by Bocanegra-Valle's research, who analysed a considerable number of reviews of the papers of Anglophone and non-Anglophone scholars and came to the conclusion that "language is a main concern in peer reviews" $(2015$, p. 225). This author has also made an attempt to reveal how reviewers evaluate the language quality of the articles under review based on the standards typical of this or that discipline.

A somewhat different perspective on the comments in reviews has been chosen by Paltridge (2015) and Samraj (2016). Paltridge investigated the linguistic patterns which reviewers choose to express their comments. The findings of this study have revealed that a significant amount of changes required by reviewers is conveyed indirectly, this potentially causing difficulties for inexperienced authors. Having considered discourse variation in reviews, Samraj (2016) demonstrated that the organization of commentary sections depend on their types. In particular, discourse units with the recommendation function dominate the "Major revision" reviews, while those with a function of evaluation are prominent in the "Reject" ones.

Research attention has also been paid to evaluative language and communicative strategies and situations (such as complimenting or conflict) in the texts of reviews (Fortanet, 2008; Fortanet-Gómez, 2008; Hewings, 2004; Johnson and Roen, 1992; Kourilova, 1998).

Johnson and Roen (1992) considered types, strategic organization and discourse function of compliments in a set of peer reviews produced by graduate students. The major focus of these authors has, however, been on the gender differences in complimenting. Their research has shown that female reviewers are more inclined, as compared to male ones, to use compliment intensifiers and to structure their reviews by providing opening and closing compliments.

Kourilova (1998) concentrated on the discourse characteristics of texts reviewing the medical research of Slovak research writers. She provided a quantitative analysis of organization patterns (which she treated, in terms of the pragmatics of politeness, as combinations of criticism and compliment) of the reviews as well as of evaluations and areas they refer to (such as omissions, unjustified conclusions, presentation shortcomings, etc.). Kourilova has also shown that positive comments in reviews may be weak and toned down in various ways. Hewings (2004) studied evaluative adjectives and the entities they evaluate based on a considerable number of reviews, submitted however, only to one journal in the field of applied linguistics. His paper offers a helpful categorization of adjectives and assessed by them entities, which disclose value orientations of reviewers and qualities they tend to judge. Fortanet (2008) conducted a quantitative study of the linguistic patterns of criticism, recommendation and requests through questions in the referee reports from two disciplines - business organization and applied linguistics. These patterns were labelled as evaluative ones, based on the broad umbrella definition of evaluation provided by Thompson and Hunston (2003). The results of this research show that reviewers give preference to criticism patterns 
in the first place, while placing recommendations and requests in the form of interrogative clauses second and third, respectively. The same research interest in evaluations has been pursued in FortanetGómez (2008).

There have also been studies considering the linguistic construction of reviewer's and reviewees' identities in the texts of reviews. Englander and López-Bonilla (2011) managed to show, in a very interesting paper, how reviewers establish quite different positions through the choice of discourse structures to recognize (or not) the author of the reviewed paper as a member of a research discourse community. In particular, they have shown how through the choice and use of some personal pronouns and their contextual synonyms reviewers accept or deny community membership of such authors. Englander and López-Bonilla also suggested the typology of reviewers' identities, which includes three types: "guardians", who view themselves as those who sustain the ideology of their communities and strongly criticize reviewed texts; "allies", providing support and resources to reviewees; and "ringmasters", who emphasize positive aspects of the manuscripts but draw attention to the relevant work of others to improve the paper. In contrast, Matsuda and Tardy (2007) studied reviewees' identities reconstructed by peers who reviewed their papers in a simulated blind review process. This research has shown that referees pay attention to those features of reviewed texts that deviate from their expectations and are guided by them in constructing writers' identities.

It should be noted that some of the above-mentioned authors, in addition to chosen research topics, considered the overall content and functional organization of the texts of peer reviews. Gosden, indicating that "there is no format for referees' reports which has been standardized by journals or publishers" (2003, p. 91), points that review texts tend to consist of a summarizing judgment and critical comments, often presented as bullet points. Kourilova (1998, p. 109) views the texts of reviews as consisting of purpose-based proto-sections which possess various combinations of criticism and compliment, while Tharirian and Sadri (2013, p. 113) distinguish between two types of organization of reviewers' reports: those emphasizing major concerns and then moving to minor ones, and those which consider a reviewed article section by section, with a consecutive presentation of both major and minor concerns. Finally, Fortanet (2008, p. 35), following a well-known Swales' (1990) analytical model, proposed a four-part move structure, which includes Summarizing judgment regarding suitability for publication, Outlining the article, Points of criticism, and Conclusion and recommendation moves.

This structure is used, as an analytical tool, in a book by Paltridge (2017) - the most comprehensive publication on the peer review, which combines pragmatic, linguistic and pedagogical perspectives on the genre. In particular, Paltridge showed the influence of context on the reviewing discourse, considered the overall organization of review texts, analysed politeness strategies and evaluations (as manifested through stance markers) in reviewers' reports, and provided recommendations for reviewer training and mentoring. The research has been carried out based on a corpus of 97 reports (however, submissions only to one journal were considered) and, what is important, has consistently focused on different groups of reviews depending on the decision they formulate ("accept", "minor revision", "major revision", and "reject").

Thus, as this literature overview shows, a certain amount of research on anonymous reviews has been accumulated. All of these studies (perhaps, with the exception of Paltridge's book, oriented at mentoring potential reviewers) have a global aim of helping young or NNSE (non-native speaker of English) authors of research papers who encounter the peer review genre and experience a lack "of cultural awareness of review and publication procedures" (Gosden, 2001, p. 4). Consequently, by elaborating research on different aspects of peer reviews, applied linguists attempt to provide for "meta-awareness of the nature of knowledge construction in the field" (Belcher, 2007, p. 19), "foster better comprehension of referee reports" (Fortanet, 2008 p. 37), and "improve authors' chances of publishing in high impact-factor journals to avoid an under-exposure" of their national research traditions (Mungra and Webber, 2010, p. 52).

\subsection{Research aims, scope and questions}

Still, the genre of the anonymous peer review requires further investigation due to a number of reasons.

First, as has been shown above, the overall organization of the texts of peer reviews has been interpreted differently and in different terms in a number of papers (Fortanet, 2008; Gosden, 2003; 
Kourilova, 1998; Paltridge, 2017; Tharirian and Sadri, 2013). It is therefore worthwhile to additionally consider it.

Second, it is well known that the language of peer reviews is often perceived by beginner and NNSE researchers as excessively critical and even painful. Not surprisingly, the authors of the reviewed articles are even advised "to be thick-skinned" (Tardy, 2008). This feeling may arise not only due to the expressivity of the language itself but also because of the insufficient awareness of communicative functions of this genre and the peculiarities of their linguistic manifestation in the texts. It is therefore important to further analyse the language of reviews in close interconnection with its three communicative purposes, thus pursuing a functional linguistic approach, which has not been consistently applied in previous research. In view of this, the following linguistic aspects of anonymous peer reviews seem to require additional scrutiny:

a) interpersonal markers, through the use of which reviewers manifest their superior position and support an appropriate style of textual interaction, allowing them to most effectively perform a "gatekeeping" function of the genre. Of particular interest here is the role of personal pronouns and their lexical substitutes, which so far have only been considered, as linguistic indicators of in- and outgroup memberships, in Englander and López-Bonilla (2011) and briefly acknowledged, as selfmentions, in Paltridge (2017). Also, it is important to look for other interpersonal devices and structures which contribute to the realization of the "gatekeeping" function of the genre;

b) evaluative lexical items, which are primary bearers of explicit evaluative meanings. Although it is difficult to disagree with Benamara et al. that concentrating on lexis "will result in an incomplete picture of the evaluative spectrum that language has to offer" (2017, p. 207), it is still worth mentioning that evaluative words possess illocutionary force, which is important for the genre of a peer review, communicatively oriented at explicit critical evaluation. Furthermore, since evaluative lexis may strongly emotionally affect the reception of reviews by authors of reviewed papers, it is important to disclose its role and functions in the texts of the genre. Given that only evaluative adjectives with reference to the entities they assess in the texts of reviews have been analysed (Hewings 2004), it is necessary to further examine how the words of negative and positive evaluation interact in the anonymous peer review and realize its evaluative function;

c) linguistic structures, which most explicitly realize the didactic function of the genre. So far, this function has not attracted the attention of linguists, while the most obvious patterns of its linguistic manifestation have been differently treated, either as evaluations (Fortanet, 2008; Fortanet-Gomez, 2008) or forms of reviewers' comments (Paltridge, 2015).

Finally, since disciplinary differences in reviewing discourse have been studied on a very limited scale, only in (Fortanet, 2008; Fortanet-Gomez, 2008), it would be interesting to compare the abovementioned features of peer review texts in different fields, especially in those which are ideologically and epistemologically distant from each other.

Thus, the present paper extends the existing research on the anonymous peer review and aims to deepen our understanding of this genre by analysing the overall functional organization of peer review texts and their prominent linguistic features shaped by three communicative functions "gatekeeping", evaluative, and didactic. Also, it will attempt to compare the characteristics of peer reviews in two research fields - applied linguistics and applied mathematics, however, with an understanding of the limitations of such an analysis when it is carried out on a small corpus.

More specifically, this study seeks to answer the following research questions:

- What semantic and functional units can be identified in the texts of peer reviews in applied linguistics and applied mathematics?

- What interpersonal markers function in these texts and how do they contribute to the realization of the "gatekeeping" function of the anonymous peer review?

- How do evaluative lexical items objectify the evaluative function of the genre?

- What linguistic structures most vividly manifest its didactic function?

- What are the differences (if any) in the features outlined above between the texts in applied linguistics and applied mathematics? 


\section{Corpus and methodology}

The peer review is one of those "occluded" academic genres that are "typically hidden, 'out of sight' or 'occluded' from the public gaze" (Swales, 1996, p. 46). Therefore, the corpus for investigation appeared to be relatively small due to difficulties in getting access to the texts of this genre.

The reviews were solicited in different ways (e.g., through personal contacts). Then, an electronic corpus was compiled, consisting of 34 texts of 29,587 words. The texts in the corpus evaluated research articles submitted to international journals in two fields - applied linguistics (AL) and applied mathematics (AM), equally, in quantitative terms, representing these disciplines (17 plus 17). The choice of the fields has been driven by two factors. First, both disciplines, being generally different, are nevertheless marked by interdisciplinarity, a broad range of problems considered, and interest in real-life issues that provides some grounds for comparing their discourses and texts. Second, the selection of these fields has been partially determined by the familiarity of the author of this article with their discourses that she has been acquainted with as an applied linguist, an ESP (English for Specific Purposes) teacher at the Applied Mathematics Department, and a researcher with appropriate experience of comparative analysis of texts in both disciplines (see Yakhontova, 2006).

The texts in the corpus resulted from the procedure of double-blind review, in which the identities of reviewer and author are concealed from each other. All of them recommended revising the evaluated articles, although in many cases it was unclear what type of revision (major or minor) was recommended. The reviews in the corpus considered initial submissions to the journals.

The analysed texts of reviews were written in English. It was not, however, possible to identify whether their authors were native or non-native speakers of the language as the names and affiliations of the reviewers were not disclosed.

The functional organization of content of the reviews was interpreted, following Fortanet (2008), as a series of consecutive moves (Moreno and Swales, 2018; Swales, 1990), that is, stable units, which "reflect the conventionalized structuring of genre determined by its communicative purpose" (Yakhontova, 2002, p. 219). It should be noted that although move analysis, has been "over-explored in recent years" (Swales, 2019, p.76), it still remains a relatively easy and effective instrument for revealing semantic and functional regularities in text organization. The moves were identified in the process of text segmentation, which included top-down detailed reading of the texts for shifts in topics with due regard for the functions of textual fragments and, in some cases, of linguistic signals. Then, the moves were coded based on the names of the functions underlying them and compared with the model suggested by Fortanet (2008). The formal layout of the texts and its correlation with revealed moves has also been considered

The linguistic features of the texts were studied from a stylistic perspective, popular in the East European linguistic context. This framework implies that linguistic parameters of texts are described not for their own sake but to show their functional significance in adequate interpretation of the text (Wales, 2001, p. 373). Accordingly, the language of peer reviews was investigated in terms of their roles in realizing the communicative functions of the genre.

First, several markers of interpersonality were analysed in view of their potentially important role in building unequal relationships in the "reviewer-author" configuration, and, thus, in the realization of the "gatekeeping" function of the genre in question. The analysis began with the consideration of personal pronouns and their lexical substitutes. After these items had been identified in the texts, their number and occurrences were counted, and a study of their functional load was conducted. Then, interrogative and negative sentences, textually prominent in reviews, were scrutinized for their role in the development of an interpersonal aspect and support they provide for manifestation of the reviewer's superior status. The revealed sentences were quantified to provide a comparative basis for the analysis. Also, a number of features, which appear sporadically but seem to contribute to the interpersonal dimension of the texts, were considered, namely, instances of informal style, stylistic devices, and use of capital letters. The quantitative and qualitative findings related to two fields were compared.

Further, an analysis of evaluative words and their use in the texts of reviews was conducted. Its procedure generally followed the one applied in Hewings (2004) for the study of evaluative adjectives. However, while this author concentrated on the entities they denote, in the present paper, a major focus will be on the role which evaluative lexis performs in the texts of reviews. Thus, all words in which evaluation is an intrinsic and explicit aspect of meaning (Warren 2006) or, put differently, those 
lexical items "which are very clearly evaluative, in the sense that evaluation is their chief function and meaning" (Thompson and Hunston, 2003, p. 14) were identified in the corpus. The compiled list of words included lexical items belonging to four main parts of speech, namely evaluative adjectives, evaluative adverbs and nouns and verbs, which contain an explicit evaluative component in their meanings (for instance, merit or jeopardize). Then, those evaluative words, which did not refer to either a reviewed paper or its author, and either to reviewer or methodological context (for example, evaluative words in the quoted fragments from the reviewed paper) were excluded from the compiled list. Words with negative prefixes were included; those with traditional neutral meanings, which seem to acquire evaluative connotations in the texts, were not considered. The identified lexical items were counted to reveal quantitative differences (if any) in the use of evaluative lexis and the type of its meaning (positive or negative) in two fields. Then the words were scrutinized for their functions in the immediate linguistic context and in the global context of the peer review genre.

Lastly, certain linguistic patterns which most explicitly manifest the didactic function of peer reviews were chosen as an object of analysis. These are syntactic constructions, which, in terms of pragmatics, belong to directives, that is, "those kinds of speech acts that speakers use to get someone else to do something" (Yule, 1996, p. 54). It is important to mention here that the use of some types of directives in the texts of peer reviews has been considered in Fortanet (2008), Fortanet-Gómez (2008) and Paltridge (2015), however, from somewhat different angles: in the first two papers they were treated as instances of evaluative language, and in the last one as ways of expressing reviewers' comments. Although, on the one hand, there are no limitations as to what can be treated as evaluation (Thompson and Hunston, 2003, p. 14), and, on the other, reviewers' remarks obviously involve directives, such speech acts above all seem to realize the didactic purpose of the genre. Moreover, previous studies of directives in peer review texts were based on different classifications: Fortanet and Fortanet-Gómez focused on recommendations, requests, and indirect requests in the form of questions, while Paltridge differentiated between what he called directions, suggestions, recommendations, and a specific type of request - the clarification one. In the present paper, the types of directives considered include commands, recommendations, suggestions and requests, as specified by Yule (1996, p. 54). Each type of directive has been identified based on the combined consideration of its meaning, syntactic structure, and appropriate lexical markers. All directives revealed in two disciplinary subgroups were quantified, analysed, and compared in terms of their functional load and disciplinary preferences.

Given the anonymity of the genre, identifying information from the fragments of reviews quoted below has been removed or reduced to the largest extent possible.

\section{Results and discussion}

\subsection{Formal layout and functional organization of the texts of reviews}

The reviews in both sub-corpora under investigation have appeared to be relatively short texts: those belonging to the field of applied linguistics vary in the range from 181 to 2,735 words (with a mean length of 927 words), while their counterparts in applied mathematics have 741 words on average, varying from 82 to 2,350 words. Overall, the total number of words in the applied linguistics subcorpus is 15,993 , while the applied mathematics one possesses 13,594 words, that is, it is 24 per cent shorter.

The texts of reviews do not seem to have any strict layout conventions, which is quite understandable, as they represent an occluded, informal genre addressing an extremely small number of recipients. In the applied linguistics group, nine texts display some features of formal structuring: six texts are divided into two parts with subheadings, such as General comments and Specific (or, for example, Analytic) comments, another one has a section entitled Summary, and two more possess a structurally visible part under the Conclusion subheading. The reviews in applied mathematics (also nine) are either subdivided into Main points and Other points sections or have only one formally marked part, entitled Other comments. It should be noted that the textual parts presenting reviewers' comments in both disciplinary groups are often additionally highlighted by subheadings in accordance with the type of comments or remarks made or the parts of reviewed texts they refer to (e.g., Language Issues, Abstract, Figures).

Formal structuring of the texts almost coincides with its functional organization represented in both disciplinary subgroups by three moves, with two of them being most prominent. These two major 
moves have earlier been identified and labelled by Fortanet (2008) as Summarizing judgment regarding suitability for publication and Points of criticism ones. However, in this paper, they will be named somewhat differently. The first move, for the sake of brevity, will be labelled as the Summarizing reviewer's opinion move, while the second one, Points of criticism, will, vice versa, have a longer, but more accurate name - Providing critical comments, remarks and recommendations, since it focuses not only on criticism but on requirements and advice aimed at improving the reviewed paper. Surprisingly, another move, suggested by Fortanet - Outlining the article - has not been found in the texts under investigation, although a very brief description of the reviewed paper may be traced in the first, Summarizing reviewer's opinion, move, e.g.:

(1) a. This article reports on a small-scale study on the acquisition of ... (AL-8);

b. The authors present a method to calculate damage evolution... (AM-7).

It should be noted that in Paltridge's study (2018, p. 42-45), the Outlining the article move appears infrequently in minor revisions reviews ( 2 in 22 texts) but is more noticeable in major revisions ones (11 in 39 texts). The discrepancy between Fortanet's and Paltridge' results, on the one hand, and the data provided in this paper, on the other, seem to depend on how the description of the reviewed article is treated; in the opinion of the author of the present article, such a description plays a role of a prelude to the reviewer's verdict and provides no grounds for singling it out as a separate unit with a specific function.

As to the final element, labelled by Fortanet (2008) as Conclusion and recommendation, it has been revealed in the present corpus, but will further be referred to as the Providing reviewer's final recommendation move, as it summarizes and emphasizes the reviewer's opinion. Thus, the move structure identified in the review texts in applied linguistics and applied mathematics possesses three components:

Move 1 - Summarizing reviewer's opinion;

Move 2 - Providing critical comments, remarks and recommendations;

Move 3 - Providing reviewer's final recommendation.

Quantitative distribution of the moves in the texts of reviews is shown in Table 1.

Table 1. Quantitative distribution of moves in the texts of reviews in applied linguistics and applied mathematics

\begin{tabular}{llcc} 
No. & \multicolumn{1}{c}{ Moves } & $\begin{array}{c}\text { Applied linguistics } \\
\text { texts }\end{array}$ & $\begin{array}{c}\text { Applied mathematics } \\
\text { texts (17) }\end{array}$ \\
1. & $\begin{array}{l}\text { Summarizing reviewer's opinion } \\
\text { 2. }\end{array}$ & 17 & 17 \\
& $\begin{array}{l}\text { Providing critical comments, remarks and } \\
\text { recommendations }\end{array}$ & 17 & 17 \\
3. Providing reviewer's final recommendation & 7 & 2 \\
\hline
\end{tabular}

As seen from the Table, the first and second moves appear in all texts of the present corpus and can thus be treated as obligatory semantic and functional elements of the texts of reviews. The third move is much less represented, especially in the applied mathematics sub-corpus. Its optional character may be caused by a certain redundancy, as the final decision on a reviewed paper is often chosen from a number of options provided by the electronic platforms through which reviews are submitted.

The results, pertinent to reviews in applied linguistics, generally agree with those obtained by Fortanet and Paltridge who have found out that the first move is quite frequent, while the move representing critical comments is obligatory. As to the final move, it is present only in 7 , that is, $44 \%$ of the texts, which also accords well with Fortanet's (2008, p. 35) findings (10 out of 25, that is, 40\%) and with Paltridge's (2017, p. 43) data on minor revisions reviews (10 out of 22, or 45\%). It is thus clear that Providing critical comments, remarks and recommendations is the most important move of peer reviews.

The first move, Summarizing reviewer's opinion, is realized in the texts by two rhetorical strategies. In the first of them, found in 14 reviews in applied linguistics and only in two reviews in 
applied mathematics, the reviewer initially pays attention to the positive features of the reviewed article and then switches to its criticism, e.g.:

(2) (Indicating positive features) There is much to like about this paper. It offers some interesting data...; it is well and interestingly referenced... (Critical evaluation) However, there are a couple of nagging issues that I think the author should address (AL-7).

As seen from the example, the conjunction "however" introduces the critical opinion of the reviewer into the text. The same role is played by other conjunctions expressing contrast or concession ("although", "but", "nevertheless", "nonetheless"), which are often used in the first move.

The second strategy, which realizes the move, consists in summarizing the content and main ideas of the reviewed paper followed by its critical evaluation, e.g.:

(3) The author studied the problem of ... (Critical evaluation) The mathematical analysis seems to be correct, although section $\mathrm{X}$ is borrowed from... No deductions or comparison of results has been made with existing ones. ... The insufficient discussion and physical interpretation of numerical results... limits the value and applicability of the paper. The presentation of the paper is also not up to required standards... (AM-1).

This strategy is prominent in almost all (15) mathematical texts and is infrequent in their linguistics counterparts.

The first move, therefore, plays the role of an introduction to the main text of the review. Its functional organization reflects the principles of politeness, generally characteristic of academic discourse.

The second obligatory move - Providing critical comments, remarks and recommendations - is undoubtedly the most important functional element of the texts of reviews, since it explains and justifies the decision of a reviewer, as can be seen from the reduced example below:

(4) I would recommend modification of the paper before it is accepted for publication. Some validation of the method should be provided. It is not clear precisely how the problem is solved. For example, the authors should specify clearly in Equation 23 what the known and unknown quantities are (AM-7).

This move occupies most of the textual space of reviews in both disciplinary groups and appears in the texts either as bullet points or a number of paragraphs, thus stimulating the author of the reviewed article to react to every remark or comment. In this paper, comments in the move were classified into six groups under labels which indicate their thematic orientation. The suggested typology differs from those elaborated earlier (Belcher, 2007; Gosden, 2003; Mungra and Webber, 2010; Tharirian and Sadri, 2013) in its emphasis on the thematic variety of reviewers' comments and their generalization. The thematic types of groups of comments are summarized and exemplified in Table 2. 
Table 2. Types of comments in the texts of anonymous peer reviews in applied linguistics and applied mathematics

\begin{tabular}{|c|c|c|c|}
\hline No. & Type of comment & Description & Example \\
\hline 1. & Conceptual & $\begin{array}{l}\text { Refers to the ideas and content of } \\
\text { the reviewed paper; may include } \\
\text { disagreement with the author's } \\
\text { conclusions or interpretations, } \\
\text { criticism of findings and/or } \\
\text { recommendations on how to } \\
\text { improve the research }\end{array}$ & $\begin{array}{l}\text { The author has decided to use text } \\
\text { feature comparability to establish } \\
\text { a genre framework without } \\
\text { sufficiently problematising his/her } \\
\text { decision (AL-14) }\end{array}$ \\
\hline 2. & Methodological & $\begin{array}{l}\text { Concerns the selected approach, } \\
\text { validity of the methods and } \\
\text { definitions, and use of } \\
\text { terminology and formulas }\end{array}$ & $\begin{array}{l}\text { The authors should consider the } \\
\text { use of the term (AM-8) }\end{array}$ \\
\hline 3. & Contextual & $\begin{array}{l}\text { Focuses on the positioning of the } \\
\text { reviewed research in the context } \\
\text { of a chosen area of inquiry; } \\
\text { provides criticism of citing in the } \\
\text { paper in case it is incorrect, } \\
\text { suggests to cite additional } \\
\text { research, or puts forward the } \\
\text { requirements as to better } \\
\text { organization of the literature } \\
\text { review }\end{array}$ & $\begin{array}{l}\text { Further support from existing } \\
\text { literature could be used to } \\
\text { emphasize the role of disciplinary } \\
\text { culture (AL-17) }\end{array}$ \\
\hline 4. & Metacommunicative & $\begin{array}{l}\text { Refers to communication of the } \\
\text { reviewee with potential recipients } \\
\text { of his/her paper; include } \\
\text { recommendations aimed at } \\
\text { strengthening the efficiency of } \\
\text { interaction between the author } \\
\text { and the audience }\end{array}$ & $\begin{array}{l}\text { Fig. } 8 \text { does not sufficiently clearly } \\
\text { indicate the improvement of the } \\
\text {...solution with increasing } \\
\text { number of terms... It seems that it } \\
\text { would be better to show this in a } \\
\text { table with possible calculation of } \\
\text { absolute or relative error (AM-12) }\end{array}$ \\
\hline 5. & Metastructural & $\begin{array}{l}\text { Criticizes the structure and } \\
\text { composition of the reviewed text } \\
\text { and suggest appropriate change; } \\
\text { may contain such requirements, } \\
\text { as additional division of the text } \\
\text { into subsections, introduction of } \\
\text { subtitles, and improvement of } \\
\text { visuals and/or appendices }\end{array}$ & $\begin{array}{l}\text { I suggest the rather long section } \\
4.1 .1 \text { could be divided into sub- } \\
\text { sections, making things more } \\
\text { reader-friendly (AL-3) }\end{array}$ \\
\hline 6. & Technical & $\begin{array}{l}\text { Refers to lexical, grammatical } \\
\text { and punctuation mistakes, errors } \\
\text { in calculations and formulas, } \\
\text { unsuccessful formulations, and } \\
\text { unnecessary repetitions and typos }\end{array}$ & $\begin{array}{l}\text { There are many misprints, and, } \\
\text { probably, mistakes in formulas } \\
\text { (AM-16) }\end{array}$ \\
\hline
\end{tabular}

It should be noted that the second move in the texts under investigation contains, in the majority of cases, all or almost all groups of critical comments, thus manifesting the importance of this part in the functional and semantic structure of the texts of peer reviews.

As to the Providing reviewer's final recommendation optional move, it once again draws attention to the changes to be made based on the provided critical analysis, and/or emphasizes the most important of them, e.g.:

(5) In sum, then, a manuscript is with potential. I hope the author finds these suggestions helpful, as well as the references I suggest can be usefully brought into the discussion (AL-3). 
Thus, the texts in the corpus possess a rather simple and straightforward functional organization marked by dominance of the second move. However, the language and stylistic features of anonymous reviews seem to provide more interesting insights into the nature of this genre.

\subsection{Language and style of anonymous peer reviews}

\subsubsection{Linguistic manifestation of interpersonality in the texts of peer reviews}

The analysis of the language of texts under investigation has revealed the highly interpersonal character of peer reviewing discourse, which most often manifests itself in the second move, thus confirming Gosden's observation on referees' revision requirements, "whose underlying rationale is more interpersonal than ideational/technical in nature" (2003, p. 99). Explicit interpersonality in the texts of reviews seems to stem from three interconnected factors: 1) the "gatekeeping" function of the genre, its communicative mission to protect academic territories from the papers of an inappropriate level; 2) the special role and social status of the reviewer as an invited expert in the field; 3) anonymity, which provokes various representations of the author's identity in the text via a spectrum of communicative strategies and linguistic devices.

Interpersonality, that is, the ways in which writers and readers project themselves in the text and interact, is most clearly indicated by such deictic devices as pronouns, which play an important role in establishing writer-reader relationships, and are of special significance for the genre of the peer review, which has two addressees - the author of the reviewed article and the journal editor (although in some journals, reviewers of one and the same paper can get access to reviews of each other). Of particular interest is the use of the first-person pronoun $I$, which signals the responsibility and authority of the review producer. As Englander and López-Bonilla mention, the double indexicality of this pronoun (that is, $I$ denotes an uttering person and the grammatical subject of the utterance), "opens the possibility of 'I' referring to him or herself with alternative lexical items such as 'the reviewer"' (2011, p. 401). Both of the elements of this contextually synonymic pair - I and reviewer - are present in the texts under investigation. At the same time, there are instances of the use of the first-person plural pronoun we, often used by writers "to get the readers to see things their way" (Harwood 2005, p. 347), which is also of considerable importance for the peer review given its didactic function.

Another revealed pair, consisting of a pronoun and its contextual lexical alternative, involves the second-person pronoun you and the word author $(s)$, which denote the subject of a reviewed paper. Also, one more deictic marker, the word reader(s), which refers to potential recipients of the reviewed work, was detected in the texts. Quantitative data characterizing the use of personal pronouns and their lexical alternatives in the texts of reviews are provided in Table 3.

Table 3. Quantitative distribution of personal pronouns and their lexical alternatives in the texts of reviews

\begin{tabular}{ccc}
\hline $\begin{array}{c}\text { Personal pronouns } \\
\text { and their lexical } \\
\text { alternatives: }\end{array}$ & $\begin{array}{c}\text { Applied } \\
\text { linguistics texts } \\
\text { (number of texts } \\
\text { / total number of } \\
\text { occurrences) }\end{array}$ & $\begin{array}{c}\text { Applied } \\
\text { mathematics texts } \\
\text { (number of texts / } \\
\text { total number of } \\
\text { occurrences) }\end{array}$ \\
I & $15 / 93$ & $9 / 20$ \\
Reviewer & 0 & $2 / 2$ \\
We & $6 / 11$ & $1 / 5$ \\
You & $4 / 11$ & $1 / 2$ \\
Author & $13 / 142$ & $13 / 80$ \\
Reader & $11 / 20$ & $1 / 1$ \\
\hline
\end{tabular}

However small this corpus is, it nevertheless shows interesting tendencies as to the role of personal pronouns and their contextual alternatives in constructing interpersonal relationships in the texts of the peer review genre. First of all, the quantitative data show the obvious presence of the first-person singular pronoun, which is significantly more prominent in applied linguistics texts. The use of this pronoun signals the positioning of reviewers, who present themselves as experts in the field empowered by their disciplinary community to evaluate and judge. At the same time, this role is 
defined not only by personal pronouns, but, as Dontcheva-Navrátilová indicates, also "by the structures in which the pronouns occur, i.e. the semantics of the verb phrase and the larger co-text" (2011, p. 14). In the texts of reviews of both disciplinary groups, I occurs in all functional moves (being most prominent in the largest, Providing critical comments, remarks and recommendations move) in combinations with epistemic verbs, e.g.:

(6) a. I think this article is interesting enough due to its topic (AL-2);

b. I believe that numerical methods coupled with crack edge autonomy is the most effective approach (AM-3).

The use of I with think and believe emphasizes the individual opinions and attitudes of the reviewer and implicates his/her higher degree of professional authority.

Another verb - feel- used with $I$ deserves special attention, as it is not generally typical of research writing oriented at objectivity and neutrality:

(7) I feel the author's case would be more convincing if s/he replaced this assertion... (AL-3).

The use of feel in the texts of anonymous reviews is, most probably, related to the special status of the text producer who, due to a dominant role, enjoys the right of expressing quite different opinions, including emotional and intuitive ones. It should be noted, however, that feel occurs only in the applied linguistics sub-corpus. At the same time, the first-person singular pronoun appears in combination with performative verbs (simple present active), which describe actions undertaken by a reviewer, in both disciplinary subgroups, e.g.:

(8) a. I recommend a different style of graphical display for this data (AL-6); b. I suggest the authors follow this convention (AM-7).

The repeated use of $I$ with performative verbs adds obvious assertiveness to the texts of peer reviews, while its occurrence with epistemic verbs makes their discourse more subjective. It should also be noted that in both groups of the texts, several instances of the use of the possessive pronoun my were identified, e.g.:

(9) a. With reference to my comment above, this is not surprising in the case of the writers writing in English (AL-3);

b. For example, in my opinion, it would be good to solve this problem by the integral transform Laplace technique (AM-16).

The possessive form intensifies the personalized character of discourse and initiates an implicit dialogue with an addressee since subjective opinions usually stimulate reactions and responses of the audience. Overall, the use of the forms of the pronoun $I$ together with the verbs considered above contribute to the formation of the specific image of the reviewer as a persona free to express various thoughts, opinions and feelings.

As to its third-person equivalent, reviewer, used only in two mathematical reviews (Table 3), it diminishes the responsibility of their producers for opinions and assertions expressed in the text and increases the distance between them and authors of reviewed work. Its use in the second move, which introduces comments and remarks, adds formality and even some solemnity to the announcement of the changes recommended:

(10) The present reviewer suggests the following changes and revisions... (AM-11).

The first-person plural pronoun is also present in the texts of reviews, however, only in a small number, being more visible in the reviews in applied linguistics (see Table 3). Nevertheless, it appears in the pragmatically important parts of the texts, namely in the second (Providing critical comments, remarks and recommendations) move, and in two thematic groups of comments - conceptual and methodological ones, e.g.: 
(11) In research, we try to be free from cultural bias. If any exists, the good researcher would be able to explain it (AL-10).

Such a we, in this and other cases, may be called representative, in terms of Dontcheva-Navrátilová (2013, p. 14), as it positions a reviewer as a member of the professional community. In the context of the peer review, this positioning, however, implies a critical stance towards the author of the reviewed article who may not qualify as a legitimate member of the community in the reviewer's opinion. This is well demonstrated by the above example, where the word researcher obviously substitutes author, excluding him/her, in the context of the quoted fragment, from the circle of those denoted by we.

Another deictic pair, you-author, indicates the virtual presence of the author of the reviewed article in the dialogue initiated and led by the reviewer. However, as Table 3 shows, you is extremely scarce in the reviews in applied mathematics and is infrequent in their linguistics counterparts. Still, this pronoun realizes two pragmatic functions. First, it explicitly points at the author of the reviewed work involving him/her into an imaginary dialogue, e.g.:

(12) a. Evaluative genre - how exactly do you define it? (AL-1);

b. Did you mean to write the following: where A1 and A2 are the Lamé coefficients (AM-1).

This effect on involvement is intensified by the question and question-like syntactic structures of the comments, which form a typical linguistic context for the use of the pronoun you. It should be noted that such cases, however infrequent they are, refute Hewings's opinion of reviews as "not addressed directly to authors" (Hewings, 2004, p. 270).

Second, in the applied linguistic texts, a second-person pronoun, in several cases, exhibits generic reference, including not only the addressee, but also the reviewer, editor, and other researchers, e.g.:

(13) This might be the number of abstracts you need to use with EAP students, in order to highlight the issues raised by the paper, but the hypotheses put forward should be checked against a larger corpus when addressing a professional audience (AM-17).

In this case, the reviewer generalizes his/her own professional knowledge and experience, extends it to embrace that of other researchers and invites the addressees, as de Hoop and Hogeweg point out, "to put themselves into someone else's shoes" $(2014$, p. 4). However, in the above fragment, this suggestion acquires negative colouring, similar to that in example (11), because in the second part of the sentence the reviewer implicitly reproaches the author of the reviewed article for not attempting to do this.

As to the contextual equivalent of you, the word author(s), it appears to be the most quantitatively visible lexical alternative (see Table 3) in both groups of reviews. The use of this word as an indirect means of addressing the reviewee generally supports dialogic relations within a textual space of the peer review, although with some peculiar features. The choice of author( $s$ ) signals two important moments: first, it emphasizes the official status of the addresser of the peer review and, consequently, underscores the special professional role of the reviewer, that is, of a particular authority; second, by presenting the addressee in the third person, the reviewer diminishes his/her imaginary right to react or respond and, in fact, turns to another addressee - the editor, thus somewhat denigrating the author of the article. Furthermore, the use of the word author( $s$ ) can manifest a scornful (as well as respectful) attitude (Englander and López-Bonilla, 2011, p. 402). Due to these functional possibilities, the word author(s) appears to be an extremely beneficial linguistic device for textual positioning of reviewers, and, not surprisingly, the quantitative data in Table 3 show its prevalence in both groups of reviews. A general picture of this word's appearance in various contextual situations looks to be rather diverse, e.g.:

(14) a. Presumably by 'adjectives,' the author is referring to possessive adjectives? Amend throughout (AL-3);

b. The authors proceed from the statement about 'the small mismatch" between calculations... The authors do not want to be bothered with quantitative argumentation and restrict themselves to referring to the curves in Fig. 2. (AM-4). 
In the first of the above-quoted fragments, the reviewer suddenly switches from the third person to the implicated you in the imperative sentence, which sounds like a strict command. This shift allows the reviewer to present himself or herself as an official persona, who has the right to give orders and demand. In the second example, the word authors indeed acquires a scornful shade, especially due to the semantics of the predicate in the sentence (do not want to be bothered).

Finally, the corpus under investigation has shown the presence of the word reader (although almost negligible in mathematical texts), which denotes the potential audience of the article under review. The use of this deictic marker seems to produce far-reaching effects for the construction of the image of a reviewer, as it helps, in Hyland's words, "to insinuate membership of a community dedicated to particular standards of scholarship and a shared pursuit of knowledge" (2004, p. 58), e.g.:

(15) a. In order for the reader to be able to interpret the findings of this type of statistical analysis, the authors need to include a paragraph in the section on 'Methodology' (AL-8);

b. There may be some presupposition there that a lot of readers do not share (AL-17).

By mentioning potential readers, the authors of the above-quoted fragments manage to simultaneously criticize the reviewed paper and to demonstrate their alignment with an appropriate research community. This allows them, as in case with the word author(s), somewhat shift off their responsibility for taking decisions and share it with other members.

Overall, as the analysis has shown, the producers of peer review texts use personal pronouns and their lexical alternatives in various ways to achieve different goals related to building and sustaining interpersonal relationships in the text - for example, to take on full responsibility for opinions and assertions or to distance themselves from them, or to speak on behalf of the professional community as its expert representatives and to involve the reviewee in an imaginary dialogue, simultaneously being able to clearly highlight his/her lower status. All these linguistic and functional possibilities, provided by the use of interpersonal devices, seem to be globally shaped by the "gatekeeping" purpose of the peer review genre, which determines the special role and status of the reviewer as a guardian of research territories.

At the same time, there are certain quantitative differences in the use of personal pronouns and their lexical alternatives in the two disciplinary groups. As can be seen from Table 3, more reviews in applied linguistics contain such deictic markers, also displaying a larger number of their occurrences, as compared with the texts in applied mathematics. This may testify to a higher degree of interpersonality in the linguistic texts. At the same time, since mathematical texts contain fewer personal pronouns but quantitatively noticeable amounts of their lexical substitutes, we may conclude that reviews in applied mathematics tend to maintain a more formal tone of discourse. The obtained data may be treated as evidence of disciplinary-determined preferences for manifesting writer-reader relationships.

Additionally, the development of an interpersonal aspect in the texts of the reviews seems to be noticeably supported by a number of other linguistic devices, in particular, by the use of interrogative constructions (namely, direct questions and negative interrogative forms) and exclamatory sentences, which appear in the second move. As seen from Table 4, interrogative structures prevail in the applied linguistics reviews, while exclamatory ones are more frequent in the mathematical texts (although their total number is much lower than that of questions).

Table 4. Quantitative distribution of interrogative and exclamatory sentences in the texts of reviews in applied linguistics and applied mathematics

\begin{tabular}{ccc}
\hline Type of sentences & Applied linguistics texts & Applied mathematics texts \\
Interrogative sentences & 106 & 92 \\
Exclamatory sentences & 7 & 19 \\
\hline
\end{tabular}

The use of direct questions in the texts of reviews appears to be rather diverse, as the quoted fragments below exemplify:

(16) a. Did you mean to write the following...? (AM-6); 
b. Has the author determined with a reasonable degree of confidence that these authors are native speakers? (AL-3);

c. Is this a useful approximation or merely an uncertain way to bypass the difficulty? (AM-3);

d. Is there really nothing useful for the research presented by the author of this paper? (AL-16).

In the first of the examples, the reviewer directly addresses the author of the reviewed paper, in the second - he/she does the same in a more formal manner, detaching himself/herself from the author, in the third one he/she formulates a question addressed not only to both readers of the review (the author and editor) but, potentially, to other members of the research community (including himself/herself), while the fourth one (d) is, in fact, a rhetorical question. In all cases, however, questions "convey an invitation to reflection or a requirement for additional information or explanation" (Fortanet, 2008, p. 30). This function and variety in the use of interrogative structures seems to essentially intensify interactional aspects of the texts of peer reviews.

As to interrogative negative forms, they create an emphatic effect and at the same time explicitly show the reviewer's intention to make the author accept his/her opinion:

(17) a. If so, why not use the term 'native speaker'... instead? (AL-3);

b. Isn't it better to replace a comma by an equality sign? (AM-4).

Exclamatory sentences in the texts of anonymous reviews convey reviewers' negative emotions, caused by defective aspects of the reviewed work, e.g.:

(18) a. This is a very big jump! (AL-10);

b. These Figures shows graphs of continuous functions! (AM-13).

In three mathematical texts, there are syntactic structures which even combine interrogation and exclamation, thus rendering a strong mixture of surprise and irritation, e.g.:

(19) Why the authors do not try to minimize the difference between analytical and FEM solutions?! (AM-4).

The interpersonal character of peer reviews reveals itself also through stylistic features. First of all, it should be noted that the language of reviews sporadically shows the presence of markers of informality, such as the use of contractions and colloquial expressions, which interplay with a generally formal tone of the texts, e.g.:

(20) a. So, a bit more background here, please (AL-7);

b. I don't believe this is standard notation (AM-2).

Such stylistic deviations from the conventions of English research writing seem to be connected with the positioning of the reviewer, who, due to a dominant status, can get away with being "linguistically liberal," trying, at the same time, to perform the role of an adviser able to communicate in an easy collegial manner.

Second, the reviews in the corpus show the presence (although infrequent) of stylistic devices, which add expressivity to the texts. Among them, there are ironical remarks and metaphorical expressions, e.g.:

(21) a. Attention should also be paid to sampling procedures: how were the abstracts "randomly" selected... (AL-17).

b. The paper provides a rather long story toward such a result. Some time is devoted to the deficiencies in the ... model, but this props up something of a strawman... (AM-3).

In several texts in both groups, the reviewers use capitalization, e.g.: 
(22) a. Revision of this concept is MANDATORY (AL-9);

b. There is SOME sort of limiting spacing between cracks in the layer (AM-3).

The use of capital letters creates a special stylistic effect of "shouting," thus attracting readers' attention to remarks or requirements to make changes. Furthermore, the use of capital letters in the texts of reviews can be treated as a deliberate linguistic strategy, similar to that occurring in digital discourse, where it evokes prosodic features and in this way signals the seriousness of writer's intentions and his/her superior status (Darics, 2010).

Also, the formation of the interpersonal aspect of reviews is closely connected with the use of directives, which will be considered in 3.2.3 in more detail.

The most interesting linguistic aspects of the genre in question are, however, connected with the use of evaluative language.

\subsubsection{Evaluative words in the texts of peer reviews}

Evaluation and its specific linguistic features in the texts of anonymous reviews seem to be strongly influenced by a group of the following factors: 1) the communicative intention of a text producer to critically evaluate a submitted paper and, in case its quality is insufficient, not to let the paper enter research territories; 2) the special status of the reviewer as an invited expert in the field; 3) his/her anonymity, which may provoke violation of the traditional norms of academic etiquette; 4) ethical norms of academic communication, which usually involve modulation of the strength of claims. These factors determine the domination of the critical aspect of reviews, manifested through a wide spectrum of evaluative lexical devices, or, in other words, a genre-specific axiological imbalance, which is shifted towards negative polarity.

Most explicitly, evaluation is manifested through the use of evaluative words. Their quantitative characteristics in the texts of peer reviews in two research disciplines are provided in Table 5.

Table 5. Quantitative distribution of evaluative words in the texts of anonymous peer reviews

\begin{tabular}{lcc}
\hline $\begin{array}{l}\text { Evaluative words } \\
\text { number/occurrences }\end{array}$ & $\begin{array}{c}\text { Applied } \\
\text { linguistics texts }\end{array}$ & $\begin{array}{c}\text { Applied } \\
\text { mathematics texts }\end{array}$ \\
$\begin{array}{l}\text { Words of positive } \\
\text { evaluation }\end{array}$ & $142 / 554$ & $63 / 172$ \\
$\begin{array}{l}\text { Words of negative } \\
\text { evaluation }\end{array}$ & $69 / 151$ & $27 / 50$ \\
Total & $211 / 705$ & $90 / 222$ \\
\hline
\end{tabular}

First, the data in Table 5 demonstrate that the texts in applied linguistics contain noticeably more evaluative words than their mathematical counterparts. Even though linguistic texts are approximately one-quarter longer than the texts in applied mathematics, this difference is obviously considerable. Second, words of positive evaluation dominate in both groups. Third, the number of occurrences of evaluative lexical items is higher in applied linguistics texts than in applied mathematics one. Also, the evaluative vocabulary of applied linguistics reviews seems to be more versatile, although both subgroups show the presence of lexical items, belonging to a highly academic register, such as coherent, paucity, obscurity (AL), or abundant, ambiguous, fidelity (AM). The functional load of the evaluative words, however, is quite similar in both subgroups.

Although communicative orientation of the peer review genre determines the overall dominance of criticism in the texts, lexically it is manifested through both words of negative and positive evaluation, which interact with each other, simultaneously supporting and (sometimes) violating stereotypes of research communication and producing various stylistic effects. Much of this impact depends upon the referential function of an evaluative lexical item and its immediate linguistic context. Evaluative words in the texts can evaluate different entities or actions, thus performing evaluative acts (a term suggested by Hewings, 2004) which referentially differ. In this paper, a functional typology of such acts with appropriate labels is suggested to better account for their role in realizing the evaluative 
function of the genre (see Table 6 for its summary and examples). It should be noted that evaluative acts are treated here, following Hewings (2004), as necessarily including evaluative words.

Table 6. Types of evaluative acts in the texts of anonymous peer reviews in applied linguistics and applied mathematics

\begin{tabular}{llll}
\hline No. $\begin{array}{c}\text { Type } \\
\text { of evaluative act } \\
\text { Article-oriented }\end{array}$ & $\begin{array}{l}\text { Aims at evaluating the quality of the reviewed } \\
\text { paper }\end{array}$ & $\begin{array}{l}\text { Description } \\
\text { It is an original } \\
\text { contribution, which seems } \\
\text { to be clearly enough } \\
\text { presented and organized }\end{array}$ \\
2. $\begin{array}{l}\text { Reviewer- } \\
\text { oriented }\end{array}$ & $\begin{array}{l}\text { Shows intellectual and emotional states of the } \\
\text { reviewer caused by the reviewed work }\end{array}$ & $\begin{array}{l}\text { I doubt they can be } \\
\text { included in the same } \\
\text { corpus (AL-15) }\end{array}$ \\
3. Context-oriented & $\begin{array}{l}\text { Evaluates other research papers, methods or function method } \\
\text { approaches, that is, creates the context, } \\
\text { against which the considered article is } \\
\text { evaluated }\end{array}$ & $\begin{array}{l}\text { is well-known and found } \\
\text { in the literature (AM-5) }\end{array}$ \\
\hline
\end{tabular}

Positive article-oriented evaluative acts seem to be most prominent in the first - Summarizing reviewer's opinion - move, which, in most cases, contains some compliments of the reviewed work and its author, made, obviously, to soften the criticism that will follow. Such evaluations are realized in the form of combinations of various types (adjectival, substantive or adverbial) with an evaluative word as a central or one of the components, e.g.:

(23) a. The article presents... sound research results grounded in clearly defined methodology, and is generally very well written (AL-11);

b. The article is original and shows a scientific contribution in the area... (AM-10).

The presence of such evaluative acts in both disciplinary sub-corpora correlates well with Hewings's observation on the role of evaluative adjectives referring to the overall quality of the article, which form "part of a broad positive assessment which then might be expanded on, although which does not preclude subsequent criticism..." (2004, p. 261). Indeed, such positive evaluative acts are often incorporated into concessive contrast constructions, which express mixed opinion indicating both positive and negative points of the same object. Using such constructions, the reviewer, as Kourilova noticed, "commits himself and then withdraws the commitment to a greater or lesser extent" (1998, p. 108), e.g.:

(24) a. Although the literature on Contrastive Rhetoric is usefully summarized, I am personally unhappy with the coverage of genre (AL-14);

b. This does not diminish the value and significance of the developed approach, although requires rethinking and reconsideration (AM-12).

The functional load of these constructions is somewhat similar to that of the introductions in "badnews" letters: they soften the reception of the following critical remarks and comments which dominate the textual space of the genre.

Article-oriented evaluative acts with negative words are becoming quite prominent in the second Providing critical comments, remarks and recommendations - move. Furthermore, they appear in all six kinds of comments (listed in Table 2) and contain numerous evaluative words belonging to different parts of speech, e.g.:

(25) a. Without ... discussion of the systems themselves, the author runs the risk of providing only superficial observations (AL-4); 
b. The authors seem to ignore that there are more general approaches in the literature (AM15):

c. These are lingering issues in the field... (AM-14);

d. There is a certain vagueness when it comes to the way quantitative differences are reported (AL-10).

e. It is very confusing ... to be presented with Table 3 on the one hand..., and then to be referred to Table 4 on the other (AL-3);

f. Reference [19] on page three is incorrect (AM-9).

The above examples consecutively illustrate use of words of negative evaluation in conceptual, methodological, contextual, metacommunicative, metastructural and technical comment groups. They contain evaluative words which belong to different parts of speech and appear in all three types of evaluative acts: article-oriented (a, b, d, and f), reviewer-oriented (e), and context-oriented (c) ones.

It should be noted that some evaluative acts (although sporadic) are highly critical and possess a vivid conflicting character. They create an axiological dissonance, which, in some cases, can be considered a violation of academic ethical standards, e.g.:

(26) a. The opening sentence... is a very poor beginning as it adds nothing new worth saying (AL9);

b. There is no basis for expecting such an ill-founded idea to work (AM-3).

In the applied linguistics texts, the expressive negative tone of discourse is supported by revieweroriented evaluative acts, which explicitly manifest the intellectual and emotional reactions of the reviewer to certain aspects of the article under review:

(27) a. I was unclear as to the extent to which the author was flagging up functional similarity (AL-3);

b. I do have some doubts about ... the topic of the article (AL-2).

Another conspicuous feature of evaluative language in peer reviews, which intensifies its critical aspect, is the use of words of positive evaluation, however paradoxical this may seem. Such lexical items are employed, in the context of the genre in question, to negatively characterize the reviewed article or the research efforts of its author. For example, using context-oriented evaluative acts, reviewers present ideas, methods and approaches which should have been mentioned in the reviewed paper in a more positive light, e.g.:

(28) a. There are some very interesting studies from the discipline of nursing (AL-3).

b. Such approaches are far more reliable than the present author seems to realize (AM-3).

Such evaluative statements imply that the author of the reviewed article has missed something important in his/her research and thus deserves criticism.

The same effect is reached through the use of reviewers' recommendations realized as constructions with modals and conditional sentences. In such utterances, the words of positive evaluation point at what has to be done to improve the paper and, consequently, indicate what it lacks:

(29) a. There needs to be some coherent discussion early in the paper... (AL-7);

b. It is desirable to give reference to the source (AM-12).

Another conspicuous feature of review texts consists in using words of positive evaluation with negative particles or in negative sentences instead of incorporating their equivalents with an opposite sign. Such a lexical strategy softens possible straightforward judgments, making them more polite, e.g.:

(30) a. The title of the article is not very informative (AL-13);

b. The comparison performed in Section 5 of the paper cannot be considered as complete (AM-12). 
The use of words of positive evaluation in such linguistic contexts produces an obvious mitigation effect and shows that reviewers, however critical they have to be, possess "an understanding of what is polite in the context of a reviewer's report" (Paltridge, 2018, p. 112).

Thus, words of positive evaluation intensify the critical orientation of anonymous reviews, which may explain their quantitative prevalence in the texts under investigation. However, the axiological imbalance characteristic of the peer review genre is closely connected with its explicit didactic orientation, marked by the striving to instruct reviewees, impose certain ideas and thoughts, and motivate them to undertake further research and writing activities, which, in reviewers' opinion, could improve the articles under consideration.

\subsubsection{The didactic function of anonymous reviews and its linguistic manifestation}

As Hewings notices, reviewers as gatekeepers "may see it as their role to guide authors towards publication, effectively acting as anonymous mentors in the development of an author's publishing career" (2004, p. 250). While evaluating papers, anonymous reviews provide feedback, which has an educational value for the authors. Furthermore, the communicative situation which gives rise to the genre of an anonymous review is that of "teacher and pupil" (Burrough, 2003, p. 223-243), which implies an instructive and didactic style of interaction. The analysis presented in this paper has confirmed that the texts of reviews in both disciplines are explicitly marked by didactic pathos, sometimes quite remarkable. Linguistically, it is most explicitly manifested through the use of directives. The quantitative data, characterizing their use, are provided in Table 7.

Table 7. Quantitative distribution of directives in the texts of reviews in applied linguistics and applied mathematics

\begin{tabular}{lcc}
\hline \multicolumn{1}{c}{ Directives } & $\begin{array}{c}\text { Applied } \\
\text { linguistics texts }\end{array}$ & $\begin{array}{c}\text { Applied } \\
\text { mathematics texts }\end{array}$ \\
Commands & 13 & 135 \\
Recommendations & 92 & 48 \\
Suggestions & 93 & 85 \\
Requests & 6 & 0 \\
Total & 204 & 268 \\
\hline
\end{tabular}

Commands, which are significantly more frequent in applied mathematics texts, are realized through imperative constructions, e.g.:

(31) a. In Conclusion better specify the major findings, write why or how these may be relevant for future research (AL-12);

b. Check these formulas (AM-12).

They appear in the second - Providing critical comments, remarks and recommendations - move, most often in the group of technical comments. In applied linguistics texts, commands do not seem to be very impolite, because, as Fortanet (2008, p. 33) rightly indicates, they require, in the majority of cases, rather small and specific changes, such as corrections of language, with substitutes or additions provided by reviewers themselves. In the reviews in applied mathematics, commands also mostly refer to the modifications of a technical character, although they can sporadically demand other kinds of changes, e.g.:

(32) For equations 22, specify the conditions (AM-1).

Overall, the commands in mathematical reviews seem to produce a more imposing impression, probably, due to their quantity, which may be determined by a larger area of technical comments itself (which includes inconsistencies in formulas, errors in data and figures, and language deficiencies). 
Recommendations, which prevail in applied linguistics reviews, are manifested through syntactic structures expressing obligation, often with the use of modals or verbs with appropriate semantics (e.g., recommend). They also appear mostly in the second move, in all groups of comments, where they refer to required changes in concepts and ideas, research methodology, literature choice and review, the ways of writer-reader interaction, structure and composition of the paper under review, and (rarely) technical errors (1-6, see Table 2). The examples below consecutively exemplify the recommendations in both subgroups depending on the types of comments they refer to:

(33) a. There are serious relevant problems that need to be solved (Al-15);

b. Some validation of the method should be provided (AM-7);

c. The author must provide the corresponding reference/s (AL-9);

d. I propose a number of changes of different character (AM-1);

e. The authors need to include a paragraph in the section on 'Methodology' which explains the rationale behind the use of ... tests (AL-8);

f. The authors are recommended to check their formulas, correct misprints and possible mistakes (AM-16).

Suggestions, which are rather similar in number in both groups, are realized in the texts of reviews through conditionals, constructions with modal verbs and lexical items, expressing possibility, and sporadically, negative interrogative sentences, e.g.:

(34) a. This possibility could be addressed through the presentation of examples (AL-10);

b. May be, it is better to use only one index!? (AM-13);

c. Isn't it better to replace a comma by an equality sign? (AM-4).

Like recommendations, suggestions appear in all types of comments in the second move. It should be noted, however, that even though suggestions sound milder than recommendations, they actually provide rather strict directions in the context of the peer review. This is due to the imbalance of power relations within this genre, as reviewers, being in a superior position, presuppose compliance with all their remarks on the part of reviewees (see Paltridge, 2015, p. 116). Given this instructive and inherently critical orientation of peer reviews, it is not surprising that requests, that is, speech acts of asking politely or formally for something, are not quantitatively prominent, yielding a small number of occurrences only in the applied linguistics texts. They are linguistically realized by imperative constructions with lexical markers of politeness and by questions with modal verbs, e.g.:

(35) a. Please, be more precise in explaining why the lower alpha was used (AL-5);

b. Can you reformulate? (AL-17).

Considering again the quantitative results (see Table 7), it is worth emphasizing that reviews in applied mathematics display a larger number of directives, even though they are 24 per cent shorter than their linguistics counterparts. They contain an incomparably larger number of commands, a noticeably smaller number of recommendations and a comparable number of suggestions. The dominance of commands may be attributed to the influence of disciplinary factors; in particular, demands for precision and accuracy of mathematical and linguistic expression can give rise to their wider use, which may to a certain extent compensate for a lesser number of recommendations (as compared with linguistics reviews).

The thematic variety and quantitative visibility of directives in the texts of reviews linguistically shape and support the didactic orientation of the genre. Even though each type of directive does not seem to be very imposing, perceived together in a text, they produce a rather strong impression of intrusive didactic pressure. This pressure is further reinforced by the interaction of directives with evaluative words, first-person pronouns, negative and interrogative sentences, and, sporadically, stylistic devices and graphical emphasis. The interplay of these linguistic means and the communicative functions they manifest linguistically shape the role of the reviewer as that of a rather authoritarian mentor who tries to influence the author of the reviewed article in a strong or determined way. Taken together, the evaluative and didactic functions of peer reviews plus the specific role of the 
reviewer and its realization via authoritarian pressure determine a special stylistic accentuation of this genre, which may be called simultaneously critical and mentoring. This accentuation helps the peer review to most effectively pursue its dominant "gatekeeping" communicative task. It should be noted that anonymity creates additional prerequisites for strict control over the quality of reviewed articles which may sometimes lead, as has been shown above, to certain deviations from academic etiquette.

Also, it is worth mentioning that the didactic function of the genre is connected with professional socialization, that is, the process of acquiring knowledge, skills and values characteristic of a certain professional domain. The function of socialization is inherent to all research genres; however, it is the peer review which seems to realize it most fully, by developing a didactic pathos, close to that of textbooks and other pedagogical materials, but stronger as to the level of its imperativeness. The didactic communicative orientation of the anonymous peer review supports the process of enculturation, or gradual assimilation to the norms of a disciplinary research culture, which is intensified by a specific expressive accentuation of the genre. Thus, the peer review can be said to possess an additional enculturation function, which, due to its explicit, imposing character, differs from the socialization role of other genres of research communication.

\section{Conclusions and implications}

The genre of the anonymous peer review plays one of the most important roles in the process of publishing and disseminating new knowledge. Its communicative orientation, textual organization and various linguistic features ensure its effective functioning in current Anglophone research communication.

This study, undertaken within a theoretical framework which combines genre analysis and the functional stylistic perspective, has demonstrated that the peer review has a number of conspicuous structural and linguistic characteristics, determined by its three major communicative functions "gatekeeping", evaluative and didactic, plus an additional one, which may be called the function of enculturation. The conducted research has confirmed that reviews possess a semantic and functional organization, represented by three major moves, and has offered a possible typology of reviewers' comments as a key element of the genre. It has considered the linguistic means which objectify the genre's functions, namely personal pronouns and their lexical substitutes, interrogative and exclamatory structures, capitalization, stylistic devices, evaluative words, and four types of directives. A typology of evaluative acts which realizes the appropriate function of the genre has also been suggested.

There was also an attempt to compare the features of peer reviews, as the corpus was formed based on texts from two epistemologically distant disciplines - applied linguistics and applied mathematics. After summarizing the findings, it is possible to cautiously state that texts in applied linguistics seem to be more interpersonal and less formal and also tend to use more evaluative words than their mathematical counterparts, which, in their turn, favour far more the rhetorical strategy of summarizing the content of the reviewed paper followed by its critical evaluation and obviously prefer commands to other types of directives.

Still, this study has two major limitations. First, the size of the corpus is small and more data are needed to arrive at sufficiently justified conclusions. This particularly concerns the observations on the differences in linguistic and mathematical reviews which so far have not been considered by other researchers. Second, in this paper, the functions and linguistic features manifesting them have been considered separately, for the purpose of a more accurate analysis. However, in a text, functions and features interplay with each other and, furthermore, one function can be realized through quite different linguistic devices. For example, directives in this paper are treated as manifestations of the didactic function, while Fortanet (2008) considers them to be evaluative language; for Paltridge (2018), evaluation is realized by stance markers, while in the present paper it is viewed through a lexical prism, as an evaluative vocabulary. Such interpretations are not contradictory but complementary as they show different angles of vision. However, it is important to emphasize that approaches which concentrate on separate functions and features (as in this article) may provide deeper insights, even though they are limited in their nature.

From a more global perspective, it is anticipated that the analysis conducted in this study will contribute to a better understanding of the genre of the anonymous peer review, which is sometimes 
perceived as a rather conflicting one due to the collision between its recognized role in research communication and critical attitude towards it by some researchers (see, for example, Ahmed and Gasparyan, 2013, p. 9). However, the awareness of its functions and linguistic conventions disclosed in the paper can help reviewees to see this genre in a more positive light, as a valuable source of professional assistance and enlightenment.

\section{Acknowledgment}

An earlier version of this paper was presented at the Department of Applied Linguistics Seminar, Birkbeck, University of London, on 5 December 2016. The author is grateful to the two anonymous reviewers for their insightful comments and remarks.

\section{References}

Ahmed, H. S., Gasparyan, A. Y. 2013. Criticism of peer review and ways to improve it. European Science Editing, vol. 39, no. 1, pp. 8-10.

Ball, Ch., 2014. Adapting editorial peer review of webtexts for classroom use. Writing \& Pedagogy, vol. 5, pp. 301-316.

Belcher, D. 2007. Seeking acceptance in an English-only research world. Journal of Second Language Writing, vol. 16, pp. 1-22.

Benamara, F., Taboada, M., Mathieu, Y. 2017. Evaluative language beyond bags of words: Linguistic insights and computational applications. Computational Linguistics, vol. 43, no. 1, pp. 201-264.

Bocanegra-Valle, A., 2015. Peer reviewers' recommendations for language improvement in research writing. In: R. Plo-Alastrué, C. Pérez-Llantada, eds. English as a scientific and research language. Debates and discourses: English in Europe, vol. 2. Berlin: Walter de Gruyter, pp. 207-232.

Burrough-Boenisch, J. 2003. Shapers of published NNS research articles. Journal of Second Language Writing, no. 12, pp. 223-243.

Darics, E. 2010. Politeness in computer-mediated discourse of a virtual team. Journal of Politeness Research, no. 6, pp. 129-150.

Dontcheva-Navrátilová, O. 2013. Authorial presence in academic discourse: functions of authorreference pronouns. Linguistica Pragensia, no. 1, pp. 9-30.

Englander, K., López-Bonilla, G. 2011. Acknowledging or denying membership: Reviewers' responses to non-anglophone scientists' manuscripts. Discourse Studies, vol. 13, no.4, pp. 395416.

Fortanet, I., 2008. Evaluative language in peer review referee reports. Journal of English for Academic Purposes, vol. 7, pp. 27-37.

Fortanet-Gómez, I. 2008. Strategies for teaching and learning an occluded genre: The RA referee report. In: S. Burgess, P. Martín-Martín, eds. English as an additional language in research publication and communication. Bern: Peter Lang, pp. 19-38.

Gosden, H., 2001. "Thank you for your critical comments and helpful suggestions": compliance and conflict in authors' replies to referees' comments in peer reviews of scientific research papers. Ibérica, vol. 3, pp. 3-17.

Gosden, H., 2003. 'Why not give us the full story?': Functions of referees' comments in peer reviews of scientific research papers. Journal of English for Academic Purposes, vol. 2, pp. 87-101.

Harwood, N. 2005. 'We Do Not Seem to Have a Theory ... The Theory I Present Here Attempts to Fill This Gap': Inclusive and Exclusive Pronouns in Academic Writing. Applied Linguistics, vol. 26, no. 3, pp. 343-375.

Hewings, M. 2004. An 'important contribution' or 'tiresome reading'? A study of evaluation in peer reviews of journal article submissions. Journal of Applied Linguistics, vol. 1, no. 3, pp. 247-274.

Hill S., Provost F., 2003. The myth of the double-blind review?: Author identification using only citations. SIGKDD Explorations, vol. 5, no. 2, pp.179-184.

Hoop, H. de, Hogeweg, L. 2014. The use of second person pronouns in a literary work. Journal of Literary Semantics, 43 (2), http://helendehoop.ruhosting.nl/Ditisvanmij_JoLS_2014.pdf.

Hyland, K. 2004. Disciplinary discourses: Social interactions in academic writing. Ann Arbor, MI: Univ. of Michigan Press. 
Johnson, D. M., Roen, D. H., 1992. Complimenting and involvement in peer reviews: Gender variation. Language in Society, vol. 21, no. 1, pp. 27-57.

Kourilova, M., 1998. Communicative characteristics of reviews of scientific papers written by nonnative users of English. Endocrine Regulations, vol. 32, pp. 107-114.

Lee, C. J., Sugimoto, S. R., Zhang, G. and Cronin B., 2013. Bias in peer review. Journal of the American Society for Information Science and Technology, vol. 64, no. 1, pp. 2-17.

Matsuda, P. K., Tardy, C. M. 2007. Voice in academic writing: The rhetorical construction of author identity in blind manuscript review. English for Specific Purposes, 26, pp. 235-249.

Moreno, A., Swales, J. M., 2018. Strengthening move analysis methodology towards bridging the function-form gap. English for Specific Purposes, vol. 50, pp. 40-63.

Mungra, Ph., Webber P., 2010. Peer review process in medical research publications: Language and content comments. English for Specific Purposes, vol. 29, pp. 43-53.

Paltridge, B., 2015. Referees' comments on submissions to peer-reviewed journals: when is a suggestion not a suggestion? Studies in Higher Education, vol. 40, no. 1, pp. 106-122.

Paltridge, B., 2017. The discourse of peer review: Reviewing submissions to academic journals. London: Palgrave Macmillan.

Parfitt, E., 2012. Establishing the genre of peer review to create new rhetorical knowledge. Compendium2, vol. 5, no. 1, pp. 1-8.

Samraj, B. 2016. Discourse structure and variation in manuscript reviews: Implications for genre categorisation. English for Specific Purposes, no. 42, pp. 76-88.

Shashok, K. 2008. Content and communication: How can peer review provide helpful feedback about the writing? BMC Medical Research Methodology, vol. 8, no. 3. [Accessed 29 April 2018].

Available at: https://bmcmedresmethodol.biomedcentral.com/articles/10.1186/1471-2288-83/open-peer-review.

Smith R., 2006. Peer review: a flawed process at the heart of science and journals. Journal of the Royal Society of Medicine, vol. 99, no. 4, pp. 178-182.

Swales, J. M., 2019. The futures of EAP genre studies: A personal viewpoint. Journal of English for Academic Purposes, no. 38, pp. 75-82.

Swales, J. M., 1990. Genre analysis. Cambridge: Cambridge University Press.

Swales, J. M., 1996. Occluded genres in the academy: The case of the submission letter. In: E. Ventola, A. Mauranen, eds. Academic writing: Intercultural and textual issues. Benjamins: Amsterdam, pp. 45-58.

Tardy, C. 2008. De-mystifying the publication process. [Accessed 21 January 2012]. Available at: purdue.edu/ eslgo/pdf/TardyPublicationGuide.pdf.

Tharirian, M. H., Sadri, E., 2013. Peer reviewers' comments on research articles submitted by Iranian researchers. The Journal of Teaching Language Skills, vol. 5, no. 3, pp. 107-123.

Thompson, G., Hunston, S. 2003. Evaluation: An introduction. In S. Hunston, G. Thompson, eds. Evaluation in text: Authorial stance and the construction of discourse. New York: Oxford University Press, pp. 1-27.

Uusiautti, S., 2016. Scientific publishing as the arena of power and caring. International Journal of Research Studies in Education, vol. 5, no. 1, pp. 75-86.

Wales, K., 2001. A dictionary of stylistics, 2nd edition. Harlow: Pearson Education.

Warren B. 2006. Prolegomena to a study of evaluative words. English Studies, vol. 87, no. 2, pp. 210229.

Yakhontova, T., 2002. 'Selling or telling'? The issue of cultural variation in research genres. In: J. Flowerdew, ed. Academic discourse. Harlow: Longman, pp. 216-232.

Yule, G. 1996. Pragmatics. Oxford: Oxford University. Press. 